\title{
A Study of Guideline and Teaching for The Olympic Education in Thailand
}

\author{
Suriyan Somphong ${ }^{(1)^{*}}$ \\ (1) Suan Sunandha Rajabhat University, Thailand \\ *Correspondence to: suriyan.so@ssru.ac.th
}

\begin{abstract}
The purposes of this study were to study the guidelines and teaching for the Olympic education that were to instil conscience of Olympic values. The 30 samples in this study were purposively sampled method. They were the experts from the National Olympic Committees of Thailand and Ministry of Education. The instruments were semi-structured interview developed by the researcher. The qualities of the instruments were verified by measuring the construct validity, calculating the index of congruence under the considerations of the experts, and determining the reliability with Cronbach's method, respectively. The results of the research showed that the guidelines for teaching Olympic education in primary schools for cultivating Olympic values for students must create a network-based collaboration.
\end{abstract}

Keywords: olympic; education; teaching; guideline

Recommended citation: Somphong, S. (2021). A Study of Guideline and Teaching for The Olympic Education in Thailand. Journal of Innovation in Educational and Cultural Research, 2(2), 60-66.

\section{INTRODUCTION}

According to the 2017 - 2036 national research plan in which the vision of the research has been defined as "All Thai nationals are required education and quality lifelong learning allowing them to live happily in accordance with the sufficiency economy philosophy and the changes of 21st century" The objective of the students are defined (3R8Cs--Reading, Writing, Arithmetic, Critical thinking and problem solving, creativity and innovation, Cross-cultural understanding, Collaboration, teamwork and leadership, communication, information and media literacy, Computing and ICT literacy, Career and learning skills, Compassion) as well as the educational management (Access, Equity, Quality, Efficiency, Relevancy) which the 6 strategies are planned as follows; 1st Strategy, education for national security and society; 2nd Strategy, production, and development of human resources, research, and innovation to develop the country's competitive strength; 3rd Strategy, development of the human resource potential of all age ranges and develop a learning society; 4th Strategy develop opportunities, equality, and education equality; 5th Strategy, the educational management to develop the living quality that is environmentally friendly; 6th Strategy, develop the efficiency of the educational administration.

Management of educational value includes morality, ethics, unity, and other characteristics. This also includes the 12 Values defined by the Thai government at the moment. The importance of the education administration is to encourage the management of the physical education, Buddhism education and the ethics in accordance to the speech of His Majestic King Rama IX on the 8th June 1979 which stated as follows "Those who already have the educational background is required to have the other characters in oneself beside the knowledge in order to be able to lead the country forward to the prosperity, the required characteristics are the selflessness, take exploiting of others but instead having the sincerity, good intention toward each one another and generosity helping each other as one can be based on one's status and duties and the most important thing is diligence, perseverance, and is required to always trying to practice and to work regardless of duty might be small and large, easy or difficult by oneself with passion, not abandoning and not for searching for convenience".

To cultivate and to nurture values to the youth of the educational organization, The United Nations Science and Culture (UNESCO) has suggested that "Physical education activities in schools and academic institutions is the most effective tool for youth to be able to obtain the skills, attitudes, values, knowledge as well as the understanding over social participation sustainably "(Berlin Declaration 2013, MINEPS V, UNESCO).

At the moment, the Olympic values is not able to be distributed to the general public because the physical education instructor, the field of sports science and the media do not aware of the importance of the 
Olympic ideology this is due to the fact that the Olympic values have yet to be included in the curriculum that produces physical education instructors as well as the field of sports science and the sports media. This group of people is the person who has the opportunity to convey the Olympic ideology to the youth and the general public. The physical education teachers and sports scientist who is responsible for teaching physical education and sports at most school levels focuses on teaching the physical skills, exercise and playing various sports in physical education and sport. (Somphong, et al., 2019)

The curriculum includes the values of sportsmanship. Knowing how to lose, to win and to forgive the students. The first point. The subject description of the physical education subject stresses on the developing of the skill and the attitude rather than the Olympic ideology. The second point is that the physical education instructor and the sports do not have the knowledge about the Olympic ideology because there is no detailed mention in the teaching of physical education in the higher education or the physical education history subject.

To able to transfer the knowledge about the Olympic ideology comprehensively among the youth, it is required to include the detail into the curriculum of the physical education subject and sport science in every school to allowing them to learn about the Olympic value. This is to provide good values and develop good morale and attitude and ethics toward the youth. The purpose of this project is to develop the teaching methodology for primary school level as well as developing the teaching media related to Olympic education for the instructor and the sports scientist in the primary school throughout the country. To study the guidelines over the teaching approach of Olympic education in primary schools. To develop an effective teaching approach by applying media for transferring Olympic Values to elementary school students.

The development of teaching guidelines of Olympic education in primary schools will be done as qualitative research. In-depth interviews are used with a policy defining stakeholders which are from the 3 related agencies which are consisted of the Thailand Olympic Academy Office of the Basic Education Commission, School Director, Head of Health and Physical Education Subject. The participation of the representatives is to define the guidelines on how to include the content of Olympic education and related extracurricular activities. This also including developing of the content related curriculum and the number of hours to be taught at the about the Olympics as well as the guidelines for promotion and development of physical education teachers and development and procurement of teaching materials.

The development of the teaching media will be compared with another type of media. The consideration of the various activities is also taken into account to assess the pros and cons of transferring knowledge about Olympic education. The media and the experimenting with the sampling group to assess the performance and the ability to transfer comprehensively.

\section{METHODS}

\section{Sampling Approach}

Thailand Olympic Academy, Office of the Basic Education Commission, Director of the School, Head of Health and Physical Education Subjects which there are 30 participants in total. The sampling population size has been gathered based on Krejcie and Morgan's theory as mentioned in Pichit (2004) which stated the purposive sampling.

\section{Data Gathering}

The primary data: The data in this section has been obtained from the interviewing administrative personnel of the Directors of the Thai Olympic Institute, Office of the Basic Education Commission, School Director, Head of Health and Physical Education subject group. There are 30 people in total from November 1,2018 , to February 31,2019 , which occupied the period over 4 months. Secondary data: The data obtained from this section is from study over the concepts. Theoretical research and related studies including various statistical subjects are used to define the conceptual framework and theory. This also includes the development of the research tools which was done by studying from various sources such as books, articles, research, journals and various documents. The collected semi-structured interview form has been considered over its completeness for further analysis. The development of the tools, the researcher has developed the interviewing form which is developed into 3 parts as mentioned above. The expert committee then examined the quality of the interviewing form before using it practically.

To study the Olympic education and review the teaching media as well as gathering the content related to Olympic education in the books and learning the material in the physical education history subject in the country. It is also to develop the interviewing and investigate the quality of the interviewing form. In-depth 
interviewing of the stakes holder with the policy of the related agencies which are the Thailand Olympic Institution, Office of the Basic Education Commission, School director, head of the health education and physical education subjects which there are 30 representatives in total. Focus Group of the physical education instructor from the schools within Bangkok and metropolitans of the 10 representatives in order to brainstorm the development of the teaching media and the activities. This is also to discuss the pros and cons of the teaching media and the various activities. To develop teaching media related to the Olympic education. To experiment with the teaching media in the school with primary school students from the public school which there are 30 participants and another group of 30 participants from a private school. The assessment is done, pre-test and post-test as well as the behavior observation form. To analyze, summarization and the Olympic education media. To organize a discussion of 10 stakeholders from the central organization are consisting of the Thailand Olympic Institute, Office of the Basic Education Commission of the School Director, Head of Health and Physical Education Subject. Arrange and summarize the research result.

\section{Data Analysis}

Analyze the data from the questionnaire by applying descriptive statistics. This is done to specify the character of the sampling group which are the average score $\left(X^{\bar{C}}\right.$ ) and standard deviation (SD). To analyze the data from the interviewing form which is done by performing content analysis which is a research technique that describes the content of the message or documents. There are 3 important characteristics. The first is to systemically apply the quantitative approach and to stress the objectivity based on the theory frame. This description will be stressed on the appearance of the message rather than the interpretation or to find a hidden message. Nevertheless, the researcher is required to be free from bias or personal opinion (Mayring, 2001). The calculation of the consistency index between the questionnaire and the objective or the content index of item objective congruence: IOC) which having the experts to investigate the completeness of the content, appropriateness along with the structure and the language of the questionnaire. The results then optimized to be used as a tool in the next stage of the research. The expert will then consider and comment and give a score.

\section{RESULT AND DISCUSSION}

The objective of this research is to obtain the guideline to develop a teaching method for Olympic education in primary schools and to develop an effective teaching media that able to transfer the Olympic values to primary school students. The discoveries will be analysed and synthesized based on the study of the Olympic ideology which represents the guidelines for developing the tools for teaching and learning Olympics at the primary school level in accordance with the intention of the Olympics.

Teaching arrangement of the Olympics education of the primary school which consisted of the development procedures as follows Policy level; 1 Encourage the educational agency and the sports to define the vision and the strategy for the organization to be able to be applied to Olympic education clearly. This is also consistent with the fundamental concept of the Olympic Charter; 2 Define the mission and objective of the teaching of Olympic education in schools; 3 Develop the strategies to transfer the Olympic values via the activities of Olympic education with the detail of the following items; 3.1 scope for the projects; 3.2 clearly stated that who the target audience is?; 3.3 define the budget plan, tracing, assessment to the preparation of the information; 3.4 prepare the media, tools for the instructor; 4 Apply the strategies that have been considered to be used in the schools; 5 Tracing and assess the strategy to transfer the Olympic via the activities of the Olympic education; 6 Adjust the work plan for better improvements.

Knowledge transferring about Olympics education and the Olympic value for the students in the educational institution at the primary school level. This is done by the collaboration with the educational network especially the cooperation with the ministry of education, Thailand Olympic Institution, Ministry of Tourism and Sports in which the person has an understanding of the activities all over Thailand as a network in this pilot project. This is to distribute the knowledge to young people in each region of Thailand.

Operational Level; 1 . Provide the knowledge for the people in which is categorized based on the group of the population which consisted of students, university students, physical education instructor and all field of subjects' teachers, parents, people, and the media; 2. Selecting high-quality teacher to develop the strategies and the system to apply the project to transfer the Olympic in the practical operation; 3. Select the target group to participate in the seminar. This does not limit only students and physical education instructors but also the administrative personnel of the schools, administrative sections from the higher education system including those from the ministry of education, ministry of tourism and sport. However, physical 
education instructor should be the first group to participate in this project; 4. To study Olympic education and allowing them to be operated effectively. There should be a collaboration between networks such as the government, Olympic Committee of Thailand, Private organization and Organization or the companies that are supporting this project; 5 . Exchange the learning process including the objective and the values to be obtained from the teaching of Olympic education with those who related such as the Committee of Thailand Olympic Institution, Ministry of Education along to the other organization to earn supports to the projects; 6 . Plan the activities in the form of the Olympic Games. This is to allow the students and their parents to participate; 7. Search for the inspiration for those who are the instructors and participate in the project; 8. Plan the operation closely with the people as well as the media; 9. Try to earn acceptance from the people and need to distribute the concept of Olympic education to the operation that is successful; 10 . Try to seek for the convenient and the Olympic education for long term operation effectively; 11 . Try to collaborate, learn and earn the information from various announcements via the internet so that the benefits could improve the Olympic education content that fits the context of Thailand; 12 . Use the symbol of Olympic for the benefits of activating and inspiring the students to learn more about Olympic education by stressing the meaning and the true intention which is deeper than the competition; 13. Arranging the teaching of Olympic Education sustainably. It is required to be done continuously and in a sustainable fashion; 14 . The education institution should arrange the area for learning about Olympic Education so that the students will absorb and understand the true value of Olympic continuously.

\section{Effective media to transfer the Olympic value to the primary school students.}

Teaching media of the Olympic value education for primary school students to be able to develop and be creative based on Olympic education. The teaching arrangement plan based on the Olympic values and the resources in the class along with the other various pattern that can be applied in Thai subject, mathematics, science, social, religion and culture, physical education, arts, housework and technology, foreign language.

The teaching approach of Olympic education consists of 3 processes in the cycle which are; Assessment (before/after) the assessment before and after teaching should be done with a various approach which assesses the activities gained from the summary, test, record, investigating assess the appropriateness; Planning and arranging to teach Study Olympic Values Education program. Produce curriculum analysis tables to check consistency in relation to principles, goals, learning standards. And course description to create a learning unit and design learning management to be in line with the 5 Olympic values. To conduct the teaching of Educational Activities Olympic values, students' roles, and participation will be concentrated in learning activities as much as possible. By letting the students interact with each other and expressing themselves by asking questions and answering questions. The conceptual framework will then be required to be designed. The process will be repeated until the answers or the knowledge about the subject will be made clear at this stage. It is necessary to have a joint analysis. In order to get the truth, fact, or answer needed. In addition, the instructor is required to analyze the content of the 5 Olympic values (joy of effort, fair play, respect, excellence and the balance of life) to be able to integrate the knowledge of Olympic values in various subjects smoothly consistent with learning plan appropriately.

\section{The teaching of Olympic education will consist of 2 approaches}

At the moment, there are rapid changes in every aspect politically, economically, socially and the people way of life. Due to the advancement of technology, it is required that the content of the curriculum be changed along with the development of the new skills required for the 21st century. The academic knowledge is important, but it is not enough for 21st learning. At the moment, the academic subject should be researchbased learning in which the instructor will be acted as an advisor as well as assisting in designing the activities. This will allow each individual student to be able to assess one's own progress. The 21st century can be categorized into 7 parts as follows; Creativity: The creative activity is an activity that allowing the student to emotionally express as well as their creativity and imagination. The drama and role play will be used as the activities; Problem solving: A procedure to manage the learning process and stimulate the problem solving rationally as well as searching the information to understand the process of the problem including the solution such as Jigsaw learning, working backward. These processes will promote aptitude and logic; To think critically: the students will learn how to think critically and analyze, synthesize and evaluate the results of the content or the situation that might be the problem of the conflict. To do this, knowledge, thinking and experience are required to lead to the decision making and properly respond that consistent with the principal and reason. This can be observed in the question and answer activity or the panel discussion; 
Cooperation, in which the teaching process focuses on working as a team. The teaching will be done in a way that the teacher assigned the task to the students and let them work as a group. The students will work together based on democracy such as the panel discussion; Citizenship: the teaching will apply various subjects that are related to each other to the content. This is in order to generate a variety of knowledge and consistent with the people's way of life and as a quality citizen. The main focus is to apply the subjects rather than the detail of the subject. The application will be done based on the instructor such as to develop the leadership skill and to become role modelling citizenship; Communication: a process to encourage the students to do the search, investigate, observe and conduct the research with various approaches. The understanding and the knowledge will be gained with the meaning and they will be able to transfer the knowledge to others systematically; Self-learning: teaching by relying on oneself is a teaching approach that allowing the students to encounter the problem and to come up with the solution by applying 5 scientific procedures 1. Problem defining and understand problem 2. Categorizing the problem and plan for solution 3. Solving the problem and gather information 4. Analyze the data or gather the knowledge together and present them 5. Concluding and evaluating or summarizing and apply for example the learning from the case study; The original knowledge and supporting the students to earn new knowledge.

A new way of teaching will apply the concepts, procedures the process and new invention to apply with the class. The problem solving or developing the learning progress effectively and consistent with the purpose of the curricular. This will allow education and learning to be more effective. The students can learn effectively more than they used to be and be inspired to learn with those innovations as well as reducing the class time.

\section{CONCLUSION}

The procedures to develop Olympic education consists of the following. The guideline to distribute the knowledge about Olympic study and the transfer of the Olympic value to the students in the primary school by developing the cooperative network within the educational institution especially the collaboration with the ministry of education, Thailand Olympic institution, Ministry of Tourism and Sport. The personnel with the understanding in the physical activities throughout Thailand and apply them as part of the network for his pilot project to develop the transferring of the knowledge to the youth in the region under the following strategies; 1st Strategy: To develop the understanding of the vision in transferring the Olympic via the Olympic education in the educational institution; 2nd strategy: To develop the cooperative network with the related organization; 3rd Strategy: To develop the knowledge about the personnel of the ministry of education, ministry of tourism and sport and the ministry of interior; 4th Strategy: Distributing the knowledge of Olympic study to the primary school students; The learning of the curricular of the Olympic study for the primary school student to develop and be creative in accordance with the Olympic ideology along with the teaching arrangement of the basic education about the Olympic value. The additional research sources in the class with the variety which can be applied in the Thai language subject, mathematics, science, social, religion and culture, health and physical education, arts, career and technology, foreign language.

At the moment, there are rapid changes in every aspect politically, economically, socially and the people way of life. Due to the advancement of the technology, it is required that the content of the curriculum be changed along with the development of the new skills required for the 21st century. The academic knowledge is important, but it is not enough for 21st learning. At the moment, the academic subject should be research-based learning in which the instructor will be acted as an advisor as well as assisting in designing the activities. This will allow each individual student to be able to assess one's own progress. The 21st century can be categorized into 7 parts as follows; Creativity: The creative activity is an activity that allowing the student to emotionally express as well as their creativity and imagination. The drama and role play will be used as the activities; Problem solving: A procedure to manage the learning process and stimulate the problem solving rationally as well as searching the information to understand the process of the problem including the solution such as Jigsaw learning, working backward. These processes will promote aptitude and logic; To think critically: the students will learn how to think critically and analyze, synthesize and evaluate the results of the content or the situation that might be the problem of the conflict. To do this, knowledge, thinking and experience are required to lead to the decision making and properly respond that consistent with the principal and reason. This can be observed in the question and answer activity or the panel discussion; Cooperation, in which the teaching process focuses on working as a team. The teaching will be done in a way that the teacher assigned the task to the students and let them work as a group. The students will work together based on democracy such as the panel discussion; Citizenship: the teaching will apply various subjects that are related to each other to the content. This is in order to generate 
a variety of knowledge and consistent with the people's way of life and as a quality citizen. The main focus is to apply the subjects rather than the detail of the subject. The application will be done based on the instructor such as to develop the leadership skill and to become role modelling citizenship; Communication: a process to encourage the students to do the search, investigate, observe and conduct the research with various approaches. The understanding and the knowledge will be gained with the meaning and they will be able to transfer the knowledge to others systematically; Self-learning: teaching by relying on oneself is a teaching approach that allows the students to encounter the problem and to come up with the solution by applying 5 scientific procedures; 1 . Problem defining and understand problem; 2 . Categorizing the problem and plan for solution; 3. Solving the problem and gather information; 4. Analyze the data or gather the knowledge together and present them; 5 . Concluding and evaluating or summarizing and apply for example the learning from the case study.

\section{REFERENCES}

Amis, J., Slack, T., \& Hinings, C. R. (2004). The pace, sequence, and linearity of radical change. Academy of management journal, 47(1), 15-39.

Australian Sports Commission. (2004). Planning in Sport. Retrieved February 20, 2020, from http://www.ausport.gov.au/nso

Berlin Declaration. (2013). The United Nations Educational. Scientific and Cultural Organization. MINEPS $\mathrm{V}, \mathrm{UNESCO}$.

Binder, D. L. (2012). Olympism: Pedagogy of an Educational Philosophy. Educational Review, 64(3), 275 302.

Geōrgiadēs, K. (2013). Olympic Revival: The Revival of the Olympic Games in Modern Times. Athens, Greece: Ekdotike Athenon S.A.

International Olympic Committee. (1994). 1894-1994-The International Olympic Committee-one hundred years: The idea-the presidents-the achievements. Lausanne, Switzerland: International Olympic Committee.

International Olympic Committee. (2013). Olympic Charter. IOC, Lausanne Switzerland.

International Olympic Committee. (2018). Olympic Charter. Lausanne, Switzerland. Retrieved 11 January 2019, From https://library.olympic.org/Default/doc/SYRACUSE/61587/sport-administrationmanualolympic-solidarity-international-olympic-committee-ed-and-publ-roger-jac?_lg=en-GB.

International Olympic Committee. (2019). Olympic Values Education Program. Lausanne, Switzerland. Retrieved 11 January 2019, https://www.olympic.org/olympic-values-and-education-program / aboutthe-toolkit

Koursi, M. (Ed.). (2003). The Olympic Games in ancient Greece. Athens, Greece: Ekdotike Athenon S.A.

Maes, M. (2009). The education and social role of the Olympic movement. Proceedings of 1st International Session for Olympic Medalists, Athens, Greece. The International Olympic Academy and the International Olympic Committee. 76-85.

Mavromataki, M. (n.d.). Greece between legend and history: 8,500 years of civilization. Athens, Greece: Haitalis.

Muller, N. (Ed.). (2000). Pierre de Coubertin 1863-1937: Olympism selected writings. Lausanne, Switzerland: International Olympic Committee.

Nattaya, K. (2006). Olympism is a philosophy of life. Kasetsart Educational Review, 21(3), 11-14.

Nipat, U. (2012). Human Model of Modern Olympic Organizations. Doctoral of Philosophy Thesis. Chulalongkorn University. Bangkok.

Pichit, R. (2004). Research Approaches in Social Sciences: Phranakhon Rajabhat University. Bangkok.

Sombat, K. (2009). A new era for sport and excellence in sport. Journal of Affairs, 6(1), 10.

Sports Authority of Thailand. (2007). The fourth National Sports Development Plan (B.E.2550-2554).

Supitr, S. (2002). Olympic Ideology. Olympic Procedures and Olympic Studies. 2002. Document for the workshop: The Olympic Committee of Thailand, Bangkok.

Supitr, S. (2017). Olympic Studies. Training Document for Sports Administration Course. 13-15 December 2017, Saen Palm Training, Nakhon Pathom Province. 
Supitr, S. (2002). Olympism, Olympic Movement and Olympic Education: National Olympic Committee of Thailand.

Suriyan, S. (2014). Olympism: Pedagogy of educational philosophy. Thailand Olympic Academy, National Olympic Committee of Thailand. Retrieved January 11, 2020, from http://www.thailandolympicacademy.blogspot.com/2014_02_01_archive.html

Suriyan, S. (2020). A major sports supporter: The Sports Authority of Thailand. African Journal of Hospitality, Tourism and Leisure, 9(2). pp.1-6.

Suriyan, S. (2020). Bidding to host a major sports event: The Youth Olympic Games. African Journal of Hospitality, Tourism and Leisure, 9(2). pp.1-10.

Suriyan, S. Komkrit, R. and Issadee, K. (2019). The Impact of the Thailand Olympic Academy on the Olympic Movement in Thailand. African Journal of Hospitality, Tourism and Leisure, 8 (1).

Suriyan, S., Issadee K., Komkrit,R. (2019). Olympism, the lost legacy in Thailand. African Journal of Hospitality, Tourism and Leisure, 8(3).

Thailand Olympic Academy. (2018). Sport Administration Course. National Olympic Committee of Thailand. Retrieved 28 March 2018, from http://www.olympicthai.org. 2018.

The International Olympic Committee (n.d.) Social Development through Sport. Retrieved January 11, 2020, from https://www.olympic.org/development-through-sport

The Secretariat of the Council of Education. (2017). National Education Plan 2017-2036. Ministry of Education. Bangkok.

Vongton, V. (2007). Sportsmanship with Chao Praya Dharmasakmontri. Bangkok: The Knowledge Center. 